Article

\title{
Inhibition of Crystal Growth during Plasma Enhanced Atomic Layer Deposition by Applying BIAS
}

\author{
Stephan Ratzsch ${ }^{1}$, Ernst-Bernhard Kley ${ }^{1}$, Andreas Tünnermann ${ }^{1,2}$ and Adriana Szeghalmi ${ }^{1,2, *}$
}

Received: 28 September 2015 ; Accepted: 12 November 2015 ; Published: 18 November 2015

Academic Editor: Peter J. King

1 Institut für Angewandte Physik, Friedrich-Schiller-Universität Jena, Max Wien Platz 1, Jena 07743,

Germany; stephan.ratzsch@uni-jena.de (S.R.); ernst-bernhard.kley@uni-jena.de (E.-B.K.);

Andreas.Tuennermann@iof.fraunhofer.de (A.T.)

2 Fraunhofer-Institut für Angewandte Optik und Feinmechanik, Albert-Einstein-Str. 7, Jena 07745, Germany

* Correspondence: a.szeghalmi@uni-jena.de; Tel.: +49-364-194-7859; Fax: +49-364-194-7802

\begin{abstract}
In this study, the influence of direct current (DC) biasing on the growth of titanium dioxide $\left(\mathrm{TiO}_{2}\right)$ layers and their nucleation behavior has been investigated. Titania films were prepared by plasma enhanced atomic layer deposition (PEALD) using $\mathrm{Ti}(\mathrm{OiPr})_{4}$ as metal organic precursor. Oxygen plasma, provided by remote inductively coupled plasma, was used as an oxygen source. The $\mathrm{TiO}_{2}$ films were deposited with and without DC biasing. A strong dependence of the applied voltage on the formation of crystallites in the $\mathrm{TiO}_{2}$ layer is shown. These crystallites form spherical hillocks on the surface which causes high surface roughness. By applying a higher voltage than the plasma potential no hillock appears on the surface. Based on these results, it seems likely, that ions are responsible for the nucleation and hillock growth. Hence, the hillock formation can be controlled by controlling the ion energy and ion flux. The growth per cycle remains unchanged, whereas the refractive index slightly decreases in the absence of energetic oxygen ions.
\end{abstract}

Keywords: plasma enhanced atomic layer deposition; titanium dioxide; anatase; plasma parameters; ion energy and nucleation; BIAS

\section{Introduction}

Due to its remarkable properties, titania $\left(\mathrm{TiO}_{2}\right)$ is a very interesting material for thin film applications. Its excellent transmittance in visible and infrared spectrum (VIS and IR), high refractive index, and chemical stability are attractive features for optical coatings [1,2]. Generally, titania has three different crystalline phases: brookite, anatase and rutile. Photocatalytic applications require anatase thin films or anatase nanoparticles with high surface-area-to-volume ratio [3-5]. A high surface-area-to-volume ratio of crystalline $\mathrm{TiO}_{2}$ results in a high surface roughness leading to high optical losses due to stray light. Thin films in optical applications require smooth surfaces. Therefore, the $\mathrm{TiO}_{2}$ amorphous phase is often preferred in optical devices, although crystalline $\mathrm{TiO}_{2}$ provides higher density and higher refractive index.

Various techniques to deposit thin $\mathrm{TiO}_{2}$ films have been applied e.g., chemical and physical vapor deposition (CVD and PVD) or atomic layer deposition (ALD) [6-10]. Especially, the interest of depositing thin $\mathrm{TiO}_{2}$ films with ALD has been growing over the past years [11-14]. Atomic layer deposition is a self-limiting, cycle-based coating technique, which enables to coat structured surfaces conformally with the desired material, e.g., for functional coatings on nanostructured surfaces [15-20]. Furthermore, this deposition technique allows excellent film uniformity and thickness scalability. Titanium dioxide can be deposited by thermal ALD as well as by plasma 
enhanced atomic layer deposition (PEALD) using a variety of metal halide and metal organic precursors. Crystalline $\mathrm{TiO}_{2}$ or crystalline grains embedded in amorphous layers are deposited at relatively low temperature in general above $150{ }^{\circ} \mathrm{C}$ [21,22]. Recently, we have reported on the formation of crystalline grains (=anatase hillocks) at $70{ }^{\circ} \mathrm{C}$ in PEALD process under specific oxygen plasma conditions [23].

Plasma enhanced atomic layer deposition provides the possibility to extend the atomic layer deposition temperature window to room temperature [24]. This feasibility opens a wide range of applications based on coating temperature sensitive materials with thin, high quality films. Room temperature deposition is enabled by highly reactive species generated in the plasma, such as radicals, ions, electrons, and photons. By controlling their flux and energy, film properties can be tailored for specific applications [23,25-28]. In remote inductively coupled plasma (remote-ICP), the plasma properties, such as ion energy distribution function (IEDF), electron temperature $\left(T_{\mathrm{e}}\right)$, ion and electron density ( $n_{\mathrm{i}}$ and $n_{\mathrm{e}}$, respectively) depend mainly on plasma gas pressure and composition, applied plasma power and the chamber configuration. Additionally, applying an external BIAS voltage to the substrate, the ion energy at the surface reaction site can be precisely controlled. In contrast to ALD, other deposition technologies like CVD or PVD commonly take advantage of controlling the ion energy and flux by applying a BIAS voltage [29-31].

The hillocks on the $\mathrm{TiO}_{2}$ surface considerably increase the surface roughness, which results in very high stray light losses [23]. Coinstantaneous they increase the effective surface area of the thin film which might be beneficial for photocatalytic applications. Accordingly it is the aim of this article, to evaluate which component in oxygen plasma, e.g., VUV-photons, electrons or ions, is responsible for their nucleation and the crystallite growth on $\mathrm{TiO}_{2}$ thin films. By controlling their flux and energy, it should be possible to control the nucleation and growth of crystallite for either photocatalytic or optical applications. First, the principles of plasmas and biasing are introduced. Then, the effect of direct current potential (DC) biasing on the $\mathrm{TiO}_{2}$ film morphology is shown in comparison to a $\mathrm{TiO}_{2}$ coating without DC-biasing. Based on these observations, the component in oxygen plasma is identified, that leads to the hillock formation in $\mathrm{TiO}_{2}$ during the plasma enhanced deposition. Finally, hillock free deposition is presented and characterized.

\section{Results and Discussion}

In the remote ICP deposition tool, the plasma source is mounted separately above the reaction chamber. It generates oxygen plasma, which is introduced to the chamber by a downstream flow. The oxygen plasma consists of radicals, ions, electrons, ozone, and oxygen, which can be either in excited or ground state [32]. It is assumed, that only three free charged carriers exist in the plasma, $\mathrm{O}_{2}{ }^{+}$created by electron impact, $\mathrm{O}^{-}$created by dissociative attachment of oxygen molecules, and electrons. In this plasma no thermal equilibrium occurs. The electrons have a higher temperature ( $T_{\mathrm{e}}$ up to several $\mathrm{eV}$ ) than the ions and neutrals components $\left(T_{\mathrm{i}} \approx 25 \mathrm{meV}\right)$, respectively. Since the electrons are at least three orders of magnitudes lighter, they have a significantly higher velocity than the ions. Consequently, they first escape from the plasma near the reactor walls. The plasma will be charged positively with respect to the reactor walls. As a result, a potential between the plasma and the walls, the self-BIAS potential emerges, which accelerates the ions towards the walls and deflect the electrons. The zone between plasma and walls is called plasma sheath. Because of the potential in the plasma sheath the electron and ion current is balanced. The maximum ion energy $\left(E_{\mathrm{i}}\right)$ can be determined using the self-BIAS potential $\left(U_{\text {self-BIAS }}\right)$, which is the difference between the plasma potential $\left(U_{\mathrm{P}}\right)$ and the substrate potential $\left(U_{\mathrm{S}}\right): E_{\mathrm{i}}=e U_{\text {self }-B I A S}=e\left(U_{\mathrm{p}}-U_{\mathrm{S}}\right)$. Generally, the substrate potential is grounded $\left(U_{S}=0 \mathrm{~V}\right)$. Negative ions are trapped inside the plasma gas, due to their higher mass and lower energy compared to the electrons.

The properties of the oxygen plasma in a deposition tool, similar to the one used in this study was detailed by Profijt et al. [33]. They analyzed the kinetic energy and the flux of the ions with retarding field energy analyzer and tungsten planar current collecting probe, respectively. Further, they 
determined the electron temperature and electron density by double Langmuir probe measurement. Light emission of the oxygen plasma was also investigated. At higher chamber pressure, the ion energy and ion flux as well as the electron temperature and electron density tend to decrease. From their data no statements or extrapolation concerning the peak ion energy in the considered pressure range between $5.7 \mathrm{~Pa}$ and $24.0 \mathrm{~Pa}$ (corresponding to the chamber pressure of oxygen gas flow rate between $10 \mathrm{sccm}$ and $100 \mathrm{sccm}$ ) can be made. Additionally, it was determined that high intensity vacuum ultraviolet light (VUV light) is emitted by the oxygen plasma. The authors pointed out that an VUV-exposure during the deposition can lead to defects or harm the coating [33].

Figure 1 depicts the surface of $\mathrm{TiO}_{2}$ layers that were deposited on $\mathrm{Si}$ substrates by two different oxygen gas flow rates $(10 \mathrm{sccm}(\mathrm{a})$; and $90 \mathrm{sccm}(\mathrm{b}))$ during the oxygen plasma pulse. For both depositions, 5000 PEALD cycles were performed that lead to a thickness of (a) $170 \mathrm{~nm}$; and (b) $160 \mathrm{~nm}$, respectively. Numerous hillocks like anatase crystallites can be observed at $10 \mathrm{sccm}$, and a few are still growing at $90 \mathrm{sccm}$ oxygen gas flow. These hillocks grow randomly on the $\mathrm{TiO}_{2}$ surface and their height strongly depends on chosen oxygen plasma conditions and deposited layer thickness. In a former study we classified these hillocks as the upper part of anatase crystallites surrounded by amorphous $\mathrm{TiO}_{2}$ layer [23]. We showed a correlation between the self-BIAS voltage for different plasma conditions and the formation of anatase hillocks on $\mathrm{TiO}_{2}$ layers at these plasma conditions [23]. Generally, high oxygen partial pressure in the plasma leads to low plasma potential which consequently causes lower maximum ion energy [32]. A high self-BIAS voltage results in numerous crystallites. However other particles, such as electrons or radicals, or photons might also activate the anatase phase growth during the deposition. Their energy or intensity might have a similar correlation to the flow rate. Here, a direct current potential is applied to the substrate, to reduce possible harmful effects of an ion bombardment.

(a)

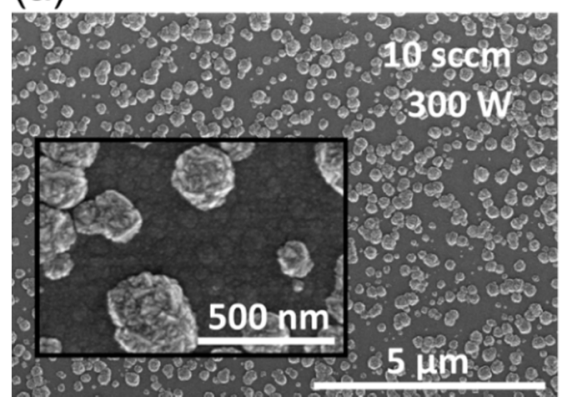

(b)

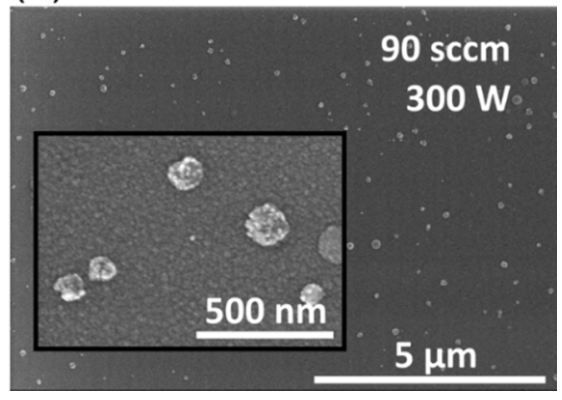

Figure 1. SEM images of the surface of $\mathrm{TiO}_{2}$ layers deposited on $\mathrm{Si}$ substrate under the following process conditions: $300 \mathrm{~W}$ plasma power; $100{ }^{\circ} \mathrm{C}$ substrate temperature; $10 \mathrm{sccm}(\mathbf{a})$, and $90 \mathrm{sccm}$ (b) oxygen gas flow corresponding to $5.7 \mathrm{~Pa}$ and 22.6 Pa chamber pressure, respectively.

The DCBIAS configuration is shown schematically in Figure 2. It was placed in the reaction chamber on the substrate heater. This configuration takes into consideration that a relatively high density of negative ions is formed in the oxygen plasma during the deposition [32]. Positively charged ions will be decelerated by applying a positive direct current potential (DC) at the electrode. If the substrate potential is sufficiently high (>plasma potential) the positive ions will be deflected. Simultaneously, electrons and negatively charged ions are attracted by the positive electric field and gain additional kinetic energy. To prevent the negatively charged ions from impinging on the substrate a metal grid is placed over the substrate. Electrons are able to escape from the plasma gas through the grid. As a consequence the plasma gas is charged positive versus the grid and so the negatively charged ions are trapped in the plasma gas. Electrons are accelerated towards the electrode and lead to a current flow. For that reason, it can be assumed, that no negatively charged ions reach the electrode or the substrate inside the DC BIAS configuration if a positive voltage is 
applied. Meanwhile radicals, ozone, oxygen molecules as well as VUV-light are unaffected by the electric field. They are available for further surface reactions.

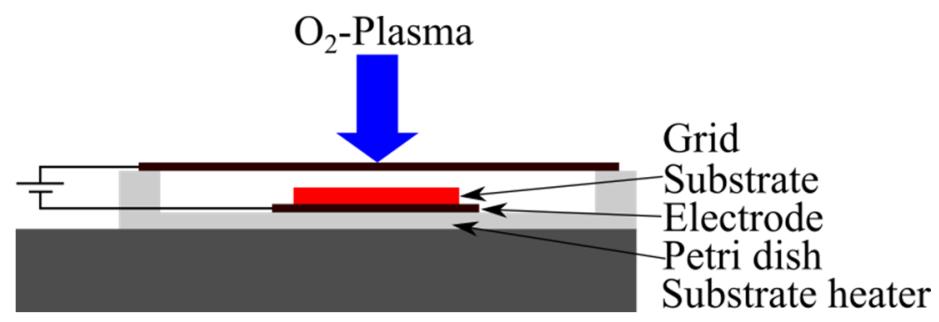

Figure 2. DC BIAS configuration in the reaction chamber.

Figure 3 highlights the change in the $\mathrm{TiO}_{2}$ layer surface morphology deposited in the BIAS configuration at different applied voltage. In both cases 5000 PEALD cycles were performed on Si substrates. The oxygen gas flow amounts $10 \mathrm{sccm}$ while the plasma power was $300 \mathrm{~W}$ during the oxygen plasma pulse. All other deposition parameters are identical to the deposition in Figure 1a, which will be labelled as reference in the following.

(a)

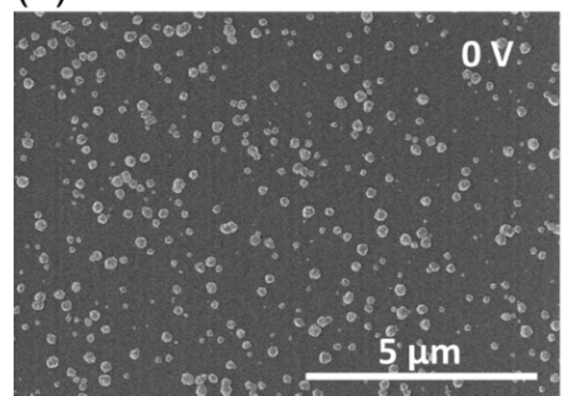

(b)

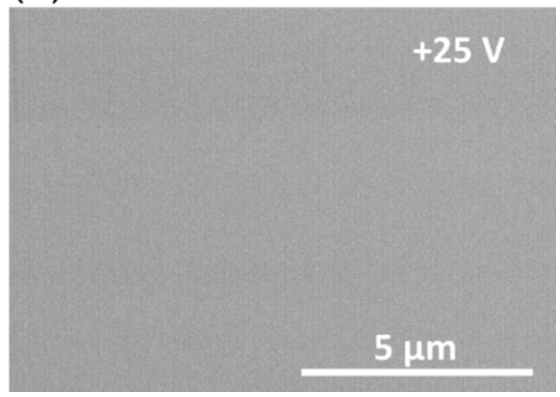

Figure 3. $\mathrm{SEM}$ images of $\mathrm{TiO}_{2}$ layers deposited on $\mathrm{Si}$ substrate under the following process conditions: $300 \mathrm{~W}$ plasma power; $100{ }^{\circ} \mathrm{C}$ substrate temperature; $10 \mathrm{sccm}$ oxygen gas flow corresponding to $5.7 \mathrm{~Pa}$ chamber pressure and DC BIAS (a) $0 \mathrm{~V}$; and (b) $+25 \mathrm{~V}$.

Compared to the reference surface in Figure 1a, the hillock density is reduced for both depositions within the DC BIAS configuration. As shown in Figure 1a many surface defects in the shape of hillocks have been formed on the reference surface. Their diameter and height is up to $300 \mathrm{~nm}$ and $120 \mathrm{~nm}$, respectively. The hillock density and lateral size reduce for the sample shown in Figure 3a, mainly due the shielding and shadowing effect of the metal grid. Only a fraction of electrons, ions and photons reaches the surface, while the substrate is beneath the metal grid. Applying a positive voltage $(+25 \mathrm{~V})$ there are no hillock-like defects on the surface. The surface seems smooth which was verified by an atomic force microscope (AFM) measurement. The results of the AFM measurements are shown in Figure 4. No detectable hillock could be observed on the surface of the $\mathrm{TiO}_{2}$ layer that was deposited at DC BIAS $+25 \mathrm{~V}$. Consequently, the RMS of this $\mathrm{TiO}_{2}$ surface is much lower than the RMS of the $\mathrm{TiO}_{2}$ surface deposited at DC BIAS $0 \mathrm{~V}$.

The layer properties are summarized in Table 1. Noticeable is the constant $\mathrm{TiO}_{2}$ layer film thickness regardless of the interference in the chamber geometry due to the introduction of DC BIAS configuration or applying a positive BIAS voltage during the deposition. Especially oxygen radicals combust isopropanol ligands during the plasma pulse [34]. They are uninfluenced by the DC BIAS, which causes a similar growth rate in the saturated regime of the ALD process. Also the surface reactions at the metal organic precursor pulse are unaffected by the DC BIAS. 
(a)

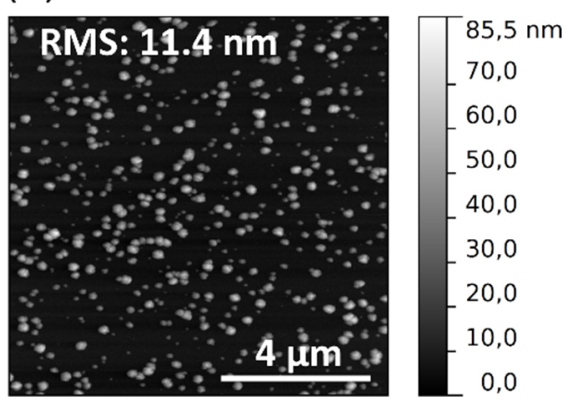

(b)

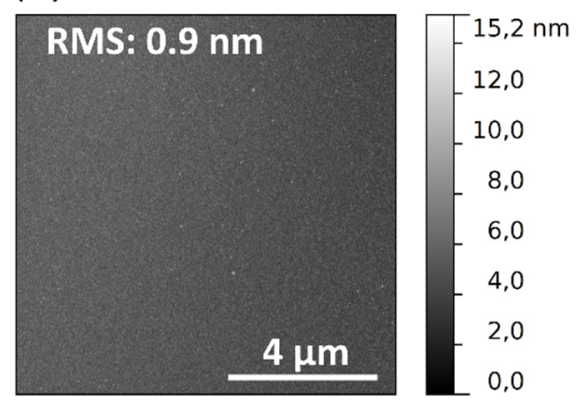

Figure 4. AFM measurement of the surface of $\mathrm{TiO}_{2}$ layers deposited on Si substrate under the following process conditions: $300 \mathrm{~W}$ plasma power; $100{ }^{\circ} \mathrm{C}$ substrate temperature; $10 \mathrm{sccm}$ oxygen gas flow corresponding to 5.7 Pa chamber pressure at DC BIAS (a) $0 \mathrm{~V}$; and (b) $+25 \mathrm{~V}$.

Table 1. Film properties of the reference sample, and the layers deposited at DC BIAS $0 \mathrm{~V}$ and $+25 \mathrm{~V}$.

\begin{tabular}{cccc}
\hline $\mathbf{T i O}_{\mathbf{2}}$ Layer Properties & Reference & $\mathbf{0 ~ V}$ & $\mathbf{+ 2 5} \mathbf{~ V}$ \\
\hline Thickness $(\mathrm{nm})$ & $171 \pm 2$ & $167 \pm 2$ & $172 \pm 2$ \\
Max height $(\mathrm{nm})$ & $120 \pm 10$ & $80 \pm 8$ & $15 \pm 1$ \\
RMS (nm) & 23.2 & 11.4 & 0.9 \\
Hillock surface coverage $(\%)$ & $52.8 \pm 5.0$ & $14.5 \pm 1.5$ & - \\
Refractive index $(\lambda=1030 \mathrm{~nm})$ & $2.37 \pm 0.02$ & $2.37 \pm 0.02$ & $2.33 \pm 0.02$ \\
\hline
\end{tabular}

The surface morphology of the films has been quantified by AFM measurements and by analysis of the scanning electron microscope (SEM) images in Figures 1 and 3. The maximum height of the hillocks for samples deposited under reference conditions is $(120 \pm 10) \mathrm{nm}$. It decreases to $84 \mathrm{~nm}$ and $15 \mathrm{~nm}$ if the Si substrate is within the DC BIAS configuration at $0 \mathrm{~V}$ and $+25 \mathrm{~V}$ voltages, respectively. The same trend is observed for the surface roughness (RMS) of the coatings. While the reference has an RMS of $23.2 \mathrm{~nm}$, it reduces to $11.4 \mathrm{~nm}$ within the DC BIAS configuration and to $0.9 \mathrm{~nm}$ at DC biasing of $+25 \mathrm{~V}$. Likewise, the hillocks surface coverage decreases. The hillock surface coverage takes all hillocks which are shown in the SEM images into account and counts the ratio between hillock free and hillock covered surface. At the reference the coverage amounts over $50 \%$ while it decreases to $14.5 \%$ when titania is deposited within the DC BIAS configuration at 0 V. Obviously, no hillocks appear in the deposition at $+25 \mathrm{~V}$ biasing.

The plasma potential for the applied oxygen plasma flow rate is $(10.0 \pm 0.5) \mathrm{V}$ [23]. Hence, the applied DC BIAS of $+25 \mathrm{~V}$ prevents the positively charged ions from reaching the substrate placed on the electrode. Electrons will gain extra kinetic energy. Consequently they impinge on the surface with a higher kinetic energy than without the applied DC voltage of $+25 \mathrm{~V}$. If they would harm the $\mathrm{TiO}_{2}$ layers, hillocks would also grow on the surface at the deposition by $+25 \mathrm{~V}$. Both the emission and the propagation of VUV light are not affected by the applied DC voltage. Accordingly, VUV light will reach also the surface even though with a lower intensity because of the shadowing effect of the metal grid. Based on these experiments, it seems likely, that ions are responsible for the nucleation and further hillock growth; whereas electrons and VUV light do not influence the hillock formation. It seems possible to control the nucleation behavior of $\mathrm{TiO}_{2}$, which is deposited by PEALD, by controlling the ion energy and ion flux during the plasma pulse. A high ion energy and ion flux lead to a high formation rate and growth rate of the anatase crystallites in the amorphous $\mathrm{TiO}_{2}$ film. They appear as hillocks on the surface and so they roughen it. This fact might be disadvantageous for an optical application of this thin film, but since anatase accrues, it could be beneficial in photocatalytic applications. The defect-free thin films could be used as optical thin film coatings. Therefore, the refractive index at $1030 \mathrm{~nm}$ was determined by Cody Lorentz oscillator model from the ellipsometer data. The absence of ions leads to a slight decrease in the refractive index at $1030 \mathrm{~nm}$. From other 
deposition techniques it is well known, that energetic ion bombardment causes denser films with a higher refractive index [35].

\section{Experimental Section}

\subsection{Deposition of $\mathrm{TiO}_{2}$-Layer}

Titanium dioxide films have been deposited on p-doped Si(100) wafer. All substrates were thoroughly cleaned with isopropanol in ultrasonic water bath and deionized water. The residual organic solvents and water were removed by a strong stream of nitrogen prior to use. Titanium tetraisopropoxide (TTiP) was used as metal organic precursor and plasma activated oxygen as oxidizer. The duration of TTiP pulse was $1.5 \mathrm{~s}$ and the duration of oxygen plasma pulse was 8 s. The oxygen gas flow rate was $10 \mathrm{sccm}$ at $300 \mathrm{~W}$ plasma power. The purge duration after the TTiP and $\mathrm{O}_{2}$-plasma pulse were $7 \mathrm{~s}$ and $4 \mathrm{~s}$, respectively. In this study, 5000 cycles are deposited on each substrate. All depositions were performed at $100{ }^{\circ} \mathrm{C}$ substrate temperature, while the operating pressure alters between $5.3 \mathrm{~Pa}$ to $40.0 \mathrm{~Pa}$.

The deposition was carried out in an open load ALD system from Oxford Instruments Plasma Technology, Yatton, UK. In the plasma enhanced deposition mode, the plasma is generated remotely in a separated chamber above the reaction chamber.

During the deposition within the DC BIAS configuration the sample was placed on the electrode. A Petri dish insulates the electrode from the grounded substrate heater. The metal grid is located $20 \mathrm{~mm}$ above the electrode on top of the Petri dish. Both, electrode and metal grid were connected to a direct current voltage generator placed outside the reactor chamber via electrical feedthrough, whereby the electrode is always connected to the anode. The metal mesh has a diamond-shaped pattern with a mesh size in the diagonals of $2 \mathrm{~mm}$ and $1.5 \mathrm{~mm}$. It has no electrical connection to the grounded reaction chamber.

\subsection{Characterization of $\mathrm{TiO}_{2}$-Layer}

The film thicknesses were analyzed by spectroscopic ellipsometry (Woollam Inc., Lincoln, NE, USA M-2000 instrument, spectral range: from $246 \mathrm{~nm}$ to $1687 \mathrm{~nm}$ ) and confirmed by measurements performed at SEM images. The ellipsometry data were fitted by a Cody Lorentz model with an effective medium approach (EMA) layer on top. The EMA layer models the surface roughness of the $\mathrm{TiO}_{2}$ layer. Layer thicknesses and refractive indices in the shown figures and tables refer to the thickness and dispersion obtained within the Cody Lorentz model for the amorphous part of the layer. Due to the higher number of fitting parameters, the estimated errors of the refractive index and the layer thickness are \pm 0.02 and $\pm 2 \mathrm{~nm}$, respectively.

The surface topology was analyzed with scanning electron microscopy (S-4800 from Hitachi, Tokyo, Japan) and atomic force microscopy (N8 TITANOS Large Sample Atomic Force Microscope from Bruker, Billerica, MA, USA). The number and the lateral size of the hillocks were determined from the SEM images (resolution: $1280 \times 890$ pixels, area: $11.5 \times 8 \mu \mathrm{m}^{2}$ ). For this purpose the greyscale SEM images were converted to binary images. In the binary image the hillocks were coded black and counted. A relative error of hillock surface coverage is estimated at $10 \%$. It includes all errors made by the image conversion and counting. The investigated area by the AFM was $10 \times 10 \mu \mathrm{m}^{2}$ with a resolution of $1024 \times 1024$ pixels. From the investigation with the AFM the maximum height of the hillocks was determined. Therefore, the ten highest points of the surface were extracted. The maximum height equals the average of these ten points. The given error represents the standard deviation of this data set.

\section{Conclusions}

In this work, we identified energetic ions as the reason for surface defect formation due to the growth of polycrystalline anatase hillocks in PEALD deposited $\mathrm{TiO}_{2}$ films. The film growth rate and 
therefore the oxidation of TTiP precursor are independent of the influence on the ion flux. However, the film surface morphology and the refractive index strongly depend on the ion flux and ion energy. Defect free titania coatings can be deposited by DC biasing under plasma conditions to obtain high quality optical thin film coatings.

Acknowledgments: We highly acknowledge the financial support within the Emmy Noether program of the German Science Foundation (SZ 253/1-1) and the NanoINT-projekt of the German Federal Ministry of Education and Research (Contract No. 13N13021). This work was partially supported by the FhG Internal Programs under Grant No. Attract 066-601020 and the Friedrich-Schiller University Prochance Program. The authors acknowledge Maria Oliva (Fraunhofer-Institut für Angewandte Optik und Feinmechanik) for the AFM measurement and Natali Sergeev for the SEM images.

Author Contributions: Stephan Ratzsch designed and performed the experiments and analyzed SEM, AFM and ellipsometer data. Stephan Ratzsch, Ernst-Bernhard Kley, Andreas Tünnermann and Adriana Szeghalmi wrote the paper.

Conflicts of Interest: The authors declare no conflict of interest.

\section{References}

1. Szeghalmi, A.; Helgert, M.; Brunner, R.; Heyroth, F.; Gosele, U.; Knez, M. Atomic layer deposition of $\mathrm{Al}_{2} \mathrm{O}_{3}$ and $\mathrm{TiO}_{2}$ multilayers for applications as bandpass filters and antireflection coatings. Appl Opt. 2009, 48, 1727-1732. [CrossRef] [PubMed]

2. Szeghalmi, A.; Helgert, M.; Brunner, R.; Heyroth, F.; Gosele, U.; Knez, M. Tunable guided-mode resonance grating filter. Adv. Funct. Mater. 2010, 20, 2053-2062. [CrossRef]

3. Lee, C.S.; Kim, J.; Gu, G.H.; Jo, D.H.; Park, C.G.; Choi, W.; Kim, H. Photocatalytic activities of TiO 2 thin films prepared on Galvanized Iron substrate by plasma-enhanced atomic layer deposition. Thin Solid Films 2010, 518, 4757-4761. [CrossRef]

4. Moser, E.M.; Chappuis, S.; Olleros, J. Production of photocatalytically active titania layers: A comparison of plasma processes and coating properties. Surf. Coat. Technol. 2013, 227, 2-9. [CrossRef]

5. Pillai, S.C.; Periyat, P.; George, R.; McCormack, D.E.; Seery, M.K.; Hayden, H.; Colreavy, J.; Corr, D.; Hinder, S.J. Synthesis of high-temperature stable anatase $\mathrm{TiO}_{2}$ photocatalyst. J. Phys. Chem. C 2007, 111, 1605-1611. [CrossRef]

6. Battiston, G.A.; Gerbasi, R.; Gregori, A.; Porchia, M.; Cattarin, S.; Rizzi, G.A. PECVD of amorphous $\mathrm{TiO}_{2}$ thin films: Effect of growth temperature and plasma gas composition. Thin Solid Films 2000, 371, 126-131. [CrossRef]

7. Bersani, D.; Antonioli, G.; Lottici, P.P.; Lopez, T. Raman study of nanosized titania prepared by sol-gel route. J. Non-Cryst. Solids 1998, 232, 175-181. [CrossRef]

8. Borras, A.; Sanchez-Valencia, J.R.; Widmer, R.; Rico, V.J.; Justo, A.; Gonzalez-Elipe, A.R. Growth of crystalline $\mathrm{TiO}_{2}$ by plasma enhanced chemical vapor deposition. Cryst. Growth Des. 2009, 9, 2868-2876. [CrossRef]

9. Martinu, L.; Poitras, D. Plasma deposition of optical films and coatings: A review. J. Vac. Sci. Technol. A 2000, 18, 2619-2645. [CrossRef]

10. Stepanov, A.L. Applications of ion implantation for modification of $\mathrm{TiO}_{2}$ : A review. Rev. Adv. Mater. Sci. 2012, 30, 150-165.

11. Aarik, J.; Aidla, A.; Uustare, T.; Ritala, M.; Leskela, M. Titanium isopropoxide as a precursor for atomic layer deposition: Characterization of titanium dioxide growth process. Appl. Surf. Sci. 2000, 161, 385-395. [CrossRef]

12. Jeon, W.J.; Chung, H.S.; Joo, D.; Kang, S.W. $\mathrm{TiO}_{2} / \mathrm{Al}_{2} \mathrm{O}_{3} / \mathrm{TiO}_{2}$ nanolaminated thin films for DRAM capacitor deposited by plasma-enhanced atomic layer deposition. Electrochem. Solid State Lett. 2008, 11, H19-H21. [CrossRef]

13. Li, X.L.; Hu, H.L.; Li, D.H.; Shen, Z.X.; Xiong, Q.H.; Li, S.Z.; Fan, H.J. ordered array of gold semishells on $\mathrm{TiO}_{2}$ spheres: An ultrasensitive and recyclable SERS substrate. ACS Appl. Mater. Interfaces 2012, 4, 2180-2185. [CrossRef] [PubMed]

14. Paul, T.; Matthes, A.; Harzendorf, T.; Ratzsch, S.; Zeitner, U.D. Half-wave phase retarder working in transmission around 630nm realized by atomic layer deposition of sub-wavelength gratings. Opt. Mater. Express 2015, 5, 124-129. [CrossRef] 
15. Ratzsch, S.; Kley, E.B.; Tünnermann, A.; Szeghalmi, A. Encapsulation process for diffraction gratings. Opt. Express 2015, 23, 17955-17965. [CrossRef] [PubMed]

16. Szeghalmi, A.; Kley, E.B.; Knez, M. Theoretical and experimental analysis of the sensitivity of guided mode resonance sensors. J. Phys. Chem. C 2010, 114, 21150-21157. [CrossRef]

17. Bourgin, Y.; Siefke, T.; Kasebier, T.; Genevee, P.; Szeghalmi, A.; Kley, E.B.; Zeitner, U.D. Double-sided structured mask for sub-micron resolution proximity i-line mask-aligner lithography. Opt Express 2015, 23, 16628-16637. [CrossRef] [PubMed]

18. Oliva, M.; Michaelis, D.; Fuchs, F.; Tunnermann, A.; Zeitner, U.D. Highly efficient broadband blazed grating in resonance domain. Appl. Phys. Lett. 2013, 102. [CrossRef]

19. Weber, T.; Kasebier, T.; Szeghalmi, A.; Knez, M.; Kley, E.B.; Tunnermann, A. Iridium wire grid polarizer fabricated using atomic layer deposition. Nanoscale Res. Lett. 2011, 6, 1-4. [CrossRef] [PubMed]

20. Mayer, M.; Grevent, C.; Szeghalmi, A.; Knez, M.; Weigand, M.; Rehbein, S.; Schneider, G.; Baretzky, B.; Schütz, G. Multilayer Fresnel zone plate for soft X-ray microscopy resolves sub-39 nm structures. Ultramicroscopy 2011, 111, 1706-1711. [CrossRef] [PubMed]

21. Aarik, J.; Aidla, A.; Mandar, H.; Sammelselg, V. Anomalous effect of temperature on atomic layer deposition of titanium dioxide. J. Cryst. Growth 2000, 220, 531-537. [CrossRef]

22. Luka, G.; Witkowski, B.S.; Wachnicki, L.; Andrzejczuk, M.; Lewandowska, M.; Godlewski, M. Kinetics of anatase phase formation in $\mathrm{TiO}_{2}$ films during atomic layer deposition and post-deposition annealing. Cryst. Eng. Comm. 2013, 15, 9949-9954. [CrossRef]

23. Ratzsch, S.; Kley, E.B.; Tünnermann, A.; Szeghalmi, A. Influence of the oxygen plasma parameters on the atomic layer deposition of titanium dioxide. Nanotechnology 2015, 26. [CrossRef] [PubMed]

24. Potts, S.E.; Profijt, H.B.; Roelofs, R.; Kessels, W.M.M. Room-temperature ALD of metal oxide thin films by energy-enhanced ALD. Chem. Vapor Depos. 2013, 19, 125-133. [CrossRef]

25. Kim, H.; Woo, S.; Lee, J.; Kim, Y.; Lee, H.; Choi, I.J.; Kim, Y.D.; Chung, C.W.; Jeon, H. Effect of DC bias on the plasma properties in remote plasma atomic layer deposition and its application to $\mathrm{HfO}_{2}$ thin films. J. Electrochem. Soc. 2011, 158, H21-H24. [CrossRef]

26. Profijt, H.B.; van de Sanden, M.C.M.; Kessele, W.M.M. Substrate-biasing during plasma-assisted atomic layer deposition to tailor metal-oxide thin film growth. J. Vac. Sci. Technol. A 2013, 31. [CrossRef]

27. Talkenberg, F.; Illhardt, S.; Radnoczi, G.Z.; Pecz, B.; Schmidl, G.; Schleusener, A.; Dikhanbayev, K.; Mussabek, G.; Gudovskikh, A.; Sivakov, V. Atomic layer deposition precursor step repetition and surface plasma pretreatment influence on semiconductor-insulator-semiconductor heterojunction solar. J. Vac. Sci. Technol. A 2015, 34. [CrossRef]

28. Profijt, H.B.; van de Sanden, M.C.M.; Kessels, W.M.M. Substrate biasing during plasma-assisted ALD for crystalline phase-control of $\mathrm{TiO}_{2}$ thin films. Electrochem. Solid State Lett. 2012, 15, G1-G3. [CrossRef]

29. Liu, J.; Huppert, G.L.; Sawin, H.H. Ion-bombardment in rf-plasmas. J. Appl. Phys. 1990, 68, 3916-3934. [CrossRef]

30. Martin, P.J. Ion-based methods for optical thin-film deposition. J. Mater. Sci. 1986, 21, 1-25. [CrossRef]

31. Martinu, L.; Klembergsapieha, J.E.; Kuttel, O.M.; Raveh, A.; Wertheimer, M.R. Critical ion energy and ion flux in the growth of films by plasma-enhanced chemical-vapor-deposition. J. Vac. Sci. Technol. 1994, 12, 1360-1364. [CrossRef]

32. Gudmundsson, J.T.; Kouznetsov, I.G.; Patel, K.K.; Lieberman, M.A. Electronegativity of low-pressure high-density oxygen discharges. J. Phys. D Appl. Phys. 2001, 34, 1100-1109. [CrossRef]

33. Profijt, H.B.; Kudlacek, P.; van de Sanden, M.C.M.; Kessels, W.M.M. Ion and photon surface interaction during remote plasma ALD of metal oxides. J. Electrochem. Soc. 2011, 158, G88-G91. [CrossRef]

34. Rai, V.R.; Agarwal, S. Surface reaction mechanisms during plasma-assisted atomic layer deposition of titanium dioxide. J. Phys. Chem. C 2009, 113, 12962-12965. [CrossRef]

35. Martin, P.J.; Macleod, H.A.; Netterfield, R.P.; Pacey, C.G.; Sainty, W.G. Ion-beam-assisted deposition of thin-films. Appl. Opt. 1983, 22, 178-184. [CrossRef] [PubMed]

(C) 2015 by the authors; licensee MDPI, Basel, Switzerland. This article is an open access article distributed under the terms and conditions of the Creative Commons by Attribution (CC-BY) license (http://creativecommons.org/licenses/by/4.0/). 